\title{
Knowledge, Attitude and Practices Related to Visceral Leishmaniasis and Its Trend in Libo Kem Kem Wereda, Northwest Ethiopia: A Cross-Sectional and Retrospective Study
}

\author{
Walelign Azene Demelash ${ }^{1, *}$, Dagim Jirata Birri \\ ${ }^{1}$ Ethiopian Biodiversity Institute, Addis Ababa, Ethiopia \\ ${ }^{2}$ Department of Microbial, Cellular and Molecular Biology, Addis Ababa University, Addis Ababa, Ethiopia \\ Email address: \\ waliaazene@gmail.com(W.A. Demelash),walelign.azene@ebi.gov.et(W.A. Demelash), dagimj@yahoo.com(D. J. Birri) \\ ${ }^{*}$ Corresponding author
}

\section{To cite this article:}

Walelign Azene Demelash, Dagim Jirata Birri. Knowledge, Attitude and Practices Related to Visceral Leishmaniasis and Its Trend in Libo Kem Kem Wereda, Northwest Ethiopia: A Cross-Sectional and Retrospective Study. International Journal of Infectious Diseases and Therapy. Vol. 4, No. 2, 2019, pp. 23-28. doi: 10.11648/j.jiidt.20190402.12

Received: May 22, 2019; Accepted: June 28, 2019; Published: July 19, 2019

\begin{abstract}
Leishmaniasis is a disease caused by protozoan parasites of the genus Leishmania. Visceral leishmaniasis (VL) affects many people in some parts of Ethiopia, with occasional outbreaks. Community participation and disease trends are of paramount importance in the control of infectious diseases, including VL. The aim of this study was to assess the knowledge, attitude and practice related to VL in four endemic kebeles (sub-districts) of Libo Kemkem wereda (district), Northwest Ethiopia, and to determine the trend of VL in the same district in the last fourteen years (April 2005- December 2018). In order to assess the knowledge, attitude and practice (KAP) related to VL, a community-based cross-sectional study was conducted in four endemic kebeles of Libo Kemkem woreda, Northwest Ethiopia. Three hundred ninety-eight (398) study participants (200 males and 198 females) were selected by systematic random sampling and questionnaires were used to collect data. A retrospective study was done to determine the trend of VL in Libo Kemkem woreda in the past fourteen years (April 2005December 2018) using data collected from patients' registration book at the Addis zemen hospital and local health centers. The results from the questionnaire survey revealed that $97.7 \%$ of the respondents heard about VL before, but only $12.8 \%$ and $5.3 \%$ knew the etiologic agent and the vector of the disease, respectively. Nearly all respondents (97.2\%) believed that health education is necessary to minimize the challenges of the disease. Close to half $(44.5 \%)$ of the respondents believed that a complete cure of the disease is possible. Approximately $88 \%$ of the respondents did not practice anything to protect themselves from the Sand fly bite. The occurrence of VL in Libo Kemkem wereda decreased from 2005 to 2008 and then gradually increased in the next five years (2008 to 2013) and slightly decreased over the last five years (2013-2018). The disease spread to 27 kebeles (subdistricts) in recent years. The overall study revealed that the local societies have a low level of knowledge, attitude, and practice related to VL. VL showed a little decreasing trend over the recent consecutive years. Hence, educating the local community about VL and mobilizing them to take preventive measures is crucial in effective control of VL in the study area.
\end{abstract}

Keywords: Knowledge, Attitude, Practice, Visceral Leishmaniasis, Trend

\section{Introduction}

Species of the genus Leishmania (Kinetoplastida, Trypanosomatidae) cause leishmaniasis and are usually transmitted between vertebrate hosts by the bite of blood sucking female sandflies (Diptera, Psychodidae) [1]. The disease is categorized into cutaneous, mucosal and visceral leishmaniasis.

Diagnose is and treatment of the disease is difficult and about $95 \%$ of VL patients are likely to die if left untreated 
[2]. Humans, wild animals and domestic dogs are known to serve as reservoir hosts. Its generalized clinical syndrome involves the reticulo-endothelial system infection (spleen, bone marrow, and liver), weight loss and anemia. Leishmanias is mainly affecting the poor, particularly those with vulnerable housing and environmental conditions. Loss of income and health care costs exacerbate the economic situation of already disadvantaged households [3].

Visceral leishmaniasis (VL) is a common deadly parasitic disease in the study area and is caused by Leishmania donovani complex. Currently, it is a growing health problem in Ethiopia with many endemic sites from which it spreads. $\mathrm{VL}$ is found in many regions of the Ethiopia such as Tigray, Amhara, Oromia, Afar, Somali and Southern Nations with the burden of 4,000 new cases per annum [4]. The largest focus of VL in Ethiopia is located in the lowland region bordering Sudan, where hundreds of thousands of agricultural workers migrate for work every year during the planting and harvesting seasons [5].

Despite its widespread, control of visceral leishmaniasis in Ethiopia had less attention. For the success of control programs against $\mathrm{VL}$, the most important prerequisites are assessment of disease-related knowledge, attitude and practice (KAP) of the community and the trend of the disease [6]. So far, very few attempts have been made to study the KAP of the community related to VL and no attempts were done and the progress the disease is not known in Bura Egzi Abhier Ab, Shina Tsion, Yifag Town and Angot kebele, which are the most VL affected sub district of Libo Kemkem wereda. Thus, this study aimed at assessing VL related knowledge, attitude and practice of the inhabitants of Bura Egzi Abhier Ab, Shina Tsion, Yifag town and Angot kebele and the trend of the VL in Libo Kemkem woreda over the past fourteen years.

\section{Materials and Methods}

\subsection{Description of the Study Area}

The present study was conducted in Bura Egzi Abhier Ab, Shina Tsion, Yifag Town and Angot kebele, which are located in Libo Kemkem Woreda, South Gondar Zone, Amhara Regional State, Northwest Ethiopia (Figure 1). The study area is characterized by having an altitude of 1800-2000 meters above sea level, mean annual temperature of 25 $28^{\circ} \mathrm{C}$, relative humidity of $31-52.7 \%$ and average annual rainfall of $900-1200 \mathrm{~mm}$.

Libo Kemkem woreda (district) consists 37 kebeles (sub districts) inhabited by a total population of 269,970 in 2018 . The district has one recently established hospital, two health centers, ten health posts and a few private drug vendors. Bura Egzi Abhier Ab, Angot, Shina Tsion and Yifag town comprise 7110 households and a population of 30,682 (15,287 females and 15,295 males) (Table 1). Bura Egzi Abhier Ab, Angot, Shina Tsion and Yifag town were selected from other kebeles since they have the highest burden of VL.

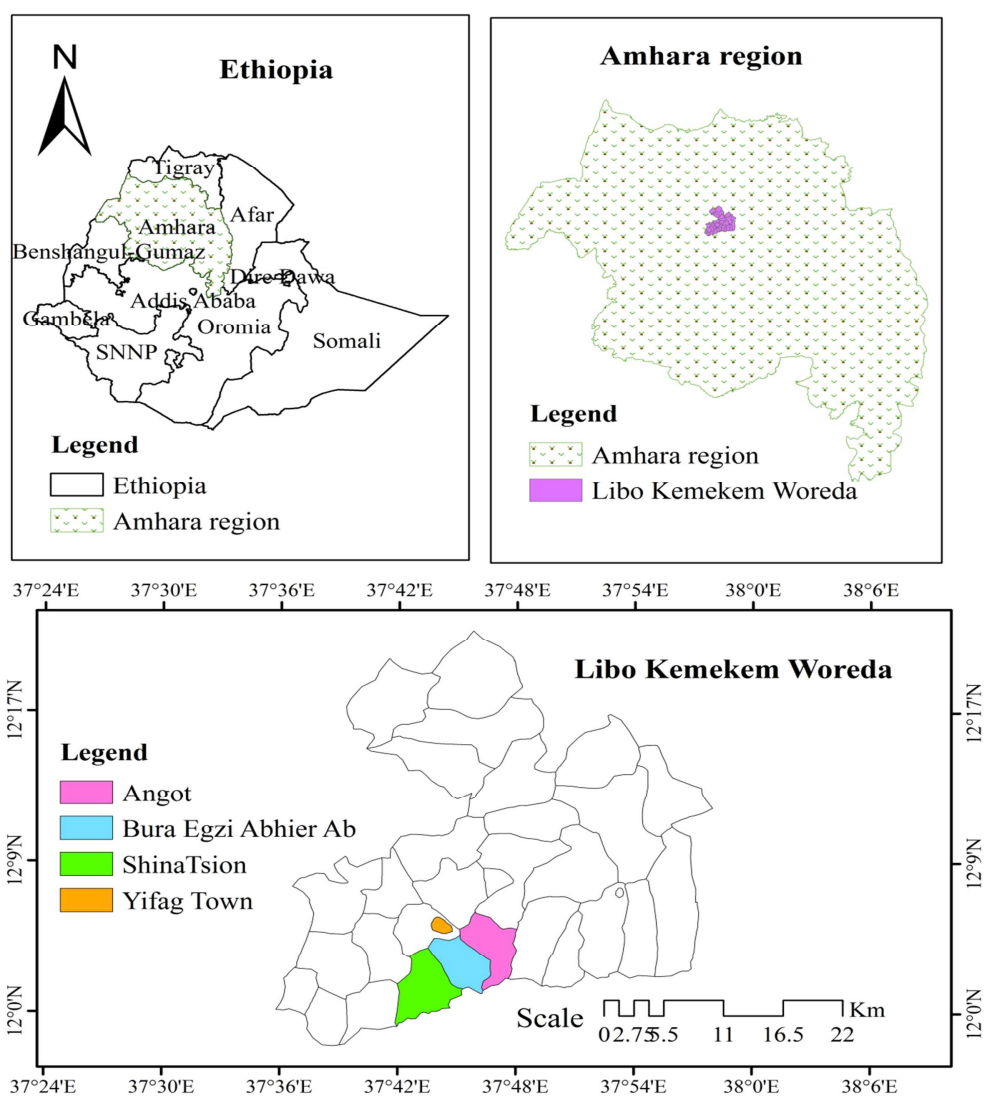

Figure 1. Map of Libo Kemkem wereda (District) and four endemic kebeles (Sub districts). 


\subsection{Design of the Study}

A community-based cross-sectional study was carried out from November to December 2018 in order to assess the knowledge, attitude and practice among inhabitants the four endemic kebleles. A retrospective study based on secondary data obtained from the hospital and health centers was used to determine the trend of VL in Libo Kemkem Wereda (District).

\subsubsection{Sample Size Determination}

Since there is no published report on visceral leishmaniasis among the rural population of the present study area, the sample size was calculated based on the assumption that at least $50 \%$ of the population had a good knowledge, attitude and practice towards visceral leishmaniasis. By using the following single population proportion formula, the sample sized was calculated to be 398 .

$$
\mathrm{n}=\mathrm{z}^{2} \mathrm{p}(1-\mathrm{p}) / \mathrm{w}^{2}
$$

Where,

$$
\begin{aligned}
& \mathrm{p}=\text { proportion }(50 \%) \\
& \mathrm{n}=\text { sample size } \\
& \mathrm{Z}=\text { confidence interval (with } 95 \% \text { level of certainty) } \\
& \mathrm{w}=\text { margin of error }(5 \%)
\end{aligned}
$$

\subsubsection{Sampling Technique}

The study participants from each study sub-districts were selected by systematic random sampling technique. Every

\begin{tabular}{|c|c|c|c|c|c|c|c|}
\hline \multirow{2}{*}{ Kebele (Sub-district) } & \multirow{2}{*}{$\begin{array}{l}\text { Number of } \\
\text { Households }\end{array}$} & \multirow{2}{*}{ Total Population } & \multicolumn{2}{|l|}{ Sex } & \multicolumn{3}{|c|}{ Sample size } \\
\hline & & & Male & Female & Male & Female & Total \\
\hline Bura Egzi Abhier Ab & 1979 & 8634 & 4387 & 4247 & 55 & 53 & 108 \\
\hline ShinaTsion & 1484 & 6218 & 3087 & 3031 & 44 & 41 & 85 \\
\hline Angot & 2026 & 8858 & 4341 & 4517 & 54 & 57 & 111 \\
\hline Total & 7110 & 30,682 & 15,295 & 15,287 & 200 & 198 & 398 \\
\hline
\end{tabular}
nineteenth household was selected and those members of the chosen households were kindly requested to fill and return the questionnaire.

Table 1. Population of the four study kebeles and sample size.

\subsection{Data Collection}

\subsubsection{Questionnaire Survey}

A structured questionnaire that was first prepared in English and then translated into the local language (Amharic) was used for primary data collection. The questionnaire contained questions on demographic characteristics, and knowledge, attitude and practice related to VL. The questionnaire was pre-tested using 40 persons outside the study area (Yifage akababi kebele) before starting the actual survey.

\subsubsection{Collection of Health Records}

In order to determine the trend of VL in Libo Kemkem Wereda, secondary data were collected from health records such as reports prepared by hospital and health Centers and patient's registration book for the past fourteen years.

\subsection{Data Analysis}

All data entry and analysis was done using SPSS version 24.

\section{Results and Discussion}

\subsection{Socio-demographic Characteristics of Study Participants}

The socio-demographic characteristics of the study participants are summarized in Table 2. A total of 398 individuals, 200 (50.3\%) males and 198 (49.7\%) females, participated in the study. The majority $(84.7 \%)$ of the study participants were older than 27 years of age. The education level of most $(81.1 \%)$ of the participants was below secondary school.

Table 2. Socio-demographic characteristics of study participants $(n=398)$.

\begin{tabular}{llll}
\hline Character & No $(\%)$ & Character & No (\%) \\
\hline Age (years) & & Kebeles & \\
$18-27$ & $61(15.3)$ & Bura EgziAbhier Ab & $108(27.1)$ \\
$28-37$ & $129(32.4)$ & ShinaTsion & $85(21.4)$ \\
$38-47$ & $103(25.9)$ & Yifag Town & $94(23.6)$ \\
$\geq 48$ & $105(26.4)$ & Angot & $111(27.9)$ \\
Sex & & & \\
Female & $198(49.7)$ & & \\
Male & $200(50.3)$ & & $153(38.4)$ \\
Occupation & & Education & $170(42.7)$ \\
Student & $25(6.3)$ & Illiterate & $56(14.1)$ \\
Farmer & $173(43.5)$ & Elementary & $19(4.8)$ \\
Housewife & $152(38.2)$ & Secondary & \\
Merchant & $38(9.5)$ & Diploma and above & \\
Government employee & $10(2.5)$ & & \\
\hline
\end{tabular}

\subsection{Knowledge of Study Participants About Visceral Leishmaniasis}

Out of 398 respondents, the majority, 389 (97.7\%), had heard about VL before and a few $37(9.3 \%)$ knew how it is acquired and transmitted (Table 3 ). The result of this study is comparable to studies conducted in a rural area of Bihar state, India and walkait district of Ethiopia, where most of the respondents $(97.4 \%)$ and $100 \%$ had heard the name VL respectively $[6,7]$. This result is higher than that of a study conducted in Addis Zemen town of Ethiopia, where 87.6\% heard about VL [8]. This might be due to the endemicity and a disease is more prevalent in rural areas which make the community more informed about the name of a disease. 
Only a negligible proportion of the respondents i.e. 21 $(5.3 \%)$, knew that VL is spread by Sand fly bite. Our finding is in agreement with a study conducted in Sudan, where only $6 \%$ of respondents indicated that the disease is transmitted by Sand fly bite [9]. The majority of the respondents, 329 $(82.7 \%)$, had no idea of the signs and symptoms of the disease, whereas $7 \%$ and $2.3 \%$ of the respondents said that abdominal swellings and fever, respectively, are the signs and symptoms of the disease. The result that the majority $(82.7 \%)$ of the respondents had no idea of the sign and symptoms of the disease is higher than that from a study conducted in endemic rural area of India, where a significant proportion of the respondents $(32.3 \%)$ had no idea about the signs and symptoms of the disease [10]. This variability might be due to lack of community health education, community awareness, socioeconomic status of the different areas, since $\mathrm{VL}$ is a recently established disease in the Libo Kemkem wereda.

Some of a study participants, 54 (13.6\%), knew some of the risk factors that predispose to VL. Our result is lower than that from a study conducted in India, where $73 \%$ of the respondents had an awareness about the causes of kala-azar [11]. This variability might be due to lack of knowledge about the disease, lack of community health education, and the absence of an integrated controlling mechanism. Regarding preventive knowledge of VL, 158 (39.7\%) of respondents said that the disease can be prevented by drying, water bodies and $17.5 \%$ of respondents had no idea at all (Table 3). About 17.5\% respondents had no idea at all about the preventive measure of VL. This result is comparable to the study conducted in Addis Zemen town of Ethiopia, where $13.5 \%$ of the respondents had no idea about the preventive measure [8].

The majority of study participants 297 (74.6\%), 316 (79.4\%) and $323(81.2 \%)$ didn't know the vector of the disease, breeding site and controlling methods of the vector respectively (Table 3 ). Our finding that $74.6 \%$ and $79.4 \%$ of respondents didn't know the vector of the disease and breeding sites respectively, which is comparable to the study conducted in walkait district of Ethiopia, where $69.32 \%$ and $74.62 \%$ of the participants didn't know the vector of the VL and the breeding sites of Sand fly [7].

Table 3. Respondents'level of knowledge about visceral leishmaniasis.

\begin{tabular}{lll}
\hline \multirow{2}{*}{ Question items } & \multicolumn{2}{c}{ Level of response } \\
\cline { 3 - 3 } & Frequency & $\begin{array}{l}\text { Percentage } \\
(\%)\end{array}$ \\
\hline $\begin{array}{l}\text { 1. Previous information about visceral } \\
\quad \text { leishmaniasis }\end{array}$ & \\
Yes & 389 & 97.7 \\
No & 9 & 2.3 \\
2. Mode of transmission the disease, VL & & \\
Yes & 37 & 9.3 \\
Sand fly & 21 & 5.3 \\
Mosquito & 16 & 4 \\
No & 361 & 90.7 \\
3. Knowledge about symptoms and signs of & & \\
$\quad$ disease, VL & 69 & 17.3 \\
Yes & & \\
\hline
\end{tabular}

\begin{tabular}{|c|c|c|}
\hline \multirow[b]{2}{*}{ Question items } & \multicolumn{2}{|c|}{ Level of response } \\
\hline & Frequency & $\begin{array}{l}\text { Percentage } \\
(\%)\end{array}$ \\
\hline Abdominal swelling & 28 & 7 \\
\hline Fever & 9 & 2.3 \\
\hline Others & 31 & 7.8 \\
\hline No & 329 & 82.7 \\
\hline \multicolumn{3}{|c|}{$\begin{array}{l}\text { 4. Knowledge about the cause of the disease, } \\
\text { VL }\end{array}$} \\
\hline Yes & 51 & 12.8 \\
\hline No & 347 & 87.2 \\
\hline \multicolumn{3}{|c|}{$\begin{array}{l}\text { 5. Knowledge about factors that predispose } \\
\text { someone to VL }\end{array}$} \\
\hline Yes & 54 & 13.6 \\
\hline No & 344 & 86.4 \\
\hline \multicolumn{3}{|c|}{$\begin{array}{l}\text { 6. Knowledge about how the disease can be } \\
\text { prevented }\end{array}$} \\
\hline Yes & 328 & 82.5 \\
\hline Insect repellant & 13 & 3.3 \\
\hline Bed net & 99 & 24.9 \\
\hline Chemical sprays & 58 & 14.6 \\
\hline Drying water bodies & 158 & 39.7 \\
\hline Do not know & 70 & 17.5 \\
\hline \multicolumn{3}{|c|}{$\begin{array}{l}\text { 7. Do you know the vector of the disease } \\
\text { VL? }\end{array}$} \\
\hline Yes & 101 & 25.4 \\
\hline No & 297 & 74.6 \\
\hline \multicolumn{3}{|c|}{$\begin{array}{l}\text { 8. Do you know breeding places of the } \\
\text { vector? }\end{array}$} \\
\hline Yes & 82 & 20.6 \\
\hline No & 316 & 79.4 \\
\hline \multicolumn{3}{|c|}{$\begin{array}{l}\text { 9. Do you know the control methods of the } \\
\text { vector? }\end{array}$} \\
\hline Yes & 75 & 18.8 \\
\hline No & 323 & 81.2 \\
\hline \multicolumn{3}{|c|}{$\begin{array}{l}\text { 10. Have you ever taken community health } \\
\text { education on VL }\end{array}$} \\
\hline Yes & 91 & 22.9 \\
\hline No & 307 & 77.1 \\
\hline
\end{tabular}

\subsection{Attitude of Study Participants Towards Visceral Leishmaniasis}

Concerning attitudes about control of VL, nearly all 387 $(97.2 \%)$ respondents believed that health education is useful to control the disease. This finding is comparable to the study conducted in wolkait district, Ethiopia where, about $73.11 \%$ respondents indicated that community participation is an essential tool to control VL [7]. The great majority of the respondents $375(94.2 \%)$ believed that VL is not the result of a curse (the evil deed) (Table 4). Regarding, the seriousness of the disease, about half (58.8\%) of respondents termed that $\mathrm{VL}$ is more serious than malaria. This result is also comparable to the reports that $71 \%$ and $80 \%$ of respondents in a rural area of Bihar state, India and a highly endemic rural area of India termed that VL is a very serious disease compared to malaria respectively $[6,10]$.

VL was thought to be completely a curable disease by $44.5 \%$ of respondents. This result is lower than that of the studies conducted in wolkait district and Addis Zemen town of Ethiopia, where the Majority $88.26 \%$ and $86.4 \%$ of participants believes that VL is a curable disease respectively $[7,8]$. This difference might be due to the community that live in the rural area (our study site) are mostly illiterate. 
About the family income, most $(95.5 \%)$ of respondents had the attitude that, when a person gets VL, not only the individual, but also the whole family has been affected economically. This result is in line with the study conducted in endemic rural area of India where, $100 \%$ of respondents said that VL infection affects family income [10]. In addition, $85.7 \%$ respondents believed that the disease can be treated (Table 4).

Table 4. Respondents' $(n=398)$ attitude towards visceral leishmaniasis.

\begin{tabular}{|c|c|c|}
\hline \multirow[b]{2}{*}{ Question items } & \multicolumn{2}{|c|}{ Level of response } \\
\hline & Frequency & $\begin{array}{l}\text { Percentage } \\
(\%)\end{array}$ \\
\hline \multicolumn{3}{|c|}{$\begin{array}{l}\text { 1. Believing that education can alleviate the } \\
\text { problem or VL }\end{array}$} \\
\hline Yes & 387 & 97.2 \\
\hline No & 11 & 2.8 \\
\hline \multicolumn{3}{|c|}{$\begin{array}{l}\text { 2. Thinking that the disease is the result of evil } \\
\text { deed }\end{array}$} \\
\hline Yes & 23 & 5.8 \\
\hline No & 375 & 94.2 \\
\hline \multicolumn{3}{|c|}{$\begin{array}{l}\text { 3. Thinking that kala-azar is a more serious } \\
\text { disease compared to malaria }\end{array}$} \\
\hline Yes & 214 & 53.8 \\
\hline No & 184 & 46.2 \\
\hline \multicolumn{3}{|c|}{$\begin{array}{l}\text { 4. Believing that complete cure of the disease is } \\
\text { possible }\end{array}$} \\
\hline Yes & 177 & 44.5 \\
\hline No & 221 & 55.5 \\
\hline \multicolumn{3}{|c|}{$\begin{array}{l}\text { 5. Thinking that the disease affects the family } \\
\text { Income }\end{array}$} \\
\hline Yes & 380 & 95.5 \\
\hline No & 18 & 4.5 \\
\hline \multicolumn{3}{|c|}{ 6. Do you think that the disease can be treated? } \\
\hline Yes & 341 & 85.7 \\
\hline No & 57 & 14.3 \\
\hline
\end{tabular}

\subsection{Practice of Study Participants in Prevention and Control Visceral Leishmaniasis}

About $39.7 \%$ of respondents preferred specific medicine for the treatment of VL, whereas $2.5 \%$ preferred Indigenous medicine for the treatment of VL (Table 5). Our fining that $2.5 \%$ preferred indigenous medicine for the treatment of $\mathrm{VL}$ which is in line with the report from endemic areas of rural India, where a negligible proportion $(1.2 \%)$ believed in traditional medicines (leaves, root and herbs) [10].

Concerning health services, public health center was the first choice for the treatment by $52.5 \%$ of respondents if suspected VL case occurred in the household, followed by private clinics $(34.7 \%)$. This study is comparable to the study in Addis Zemen town, Ethiopia where, majority 94.4\% preferred to get treatment at health centers [8]. But a study conducted in a rural area of Bihar state, India revealed that Private Doctors were the first choice for treatment by $47.6 \%$ of the respondents if a suspected case of Kala-azar occurred in the household, followed by non-government organizations (NGOs) /charitable hospitals $24.0 \%$ [6]. This difference is because of their views of the inadequacy of the health system and public health systems are not enough facilities.

Only few $8 \%$ and $5.8 \%$ respondents use a bed net and avoid outdoor sleeping habit to avoid Sand fly biting respectively. This study is in line with a study conducted in Welkait District, Ethiopia where, more than half, $62.88 \%$ had an experience of outdoor sleeping specially during high temperature [7]. Even majority $70.6 \%$ of respondents doesn't use any kind of preventive methods (Table 5). This study is comparable to the study conducted in Welkait District, Ethiopia where, majority $94.50 \%$ of the respondents declared that, they had never ever applied insecticide spray into their house/ surrounding area [7].

In addition, $12.1 \%$ of respondents used some practice (using bed net) to avoid the access of Sand fly to human which is in agreement with the studies reported from Welkait District and Addis Zemen town of Ethiopia who showed $23.11 \%$ and $19.8 \%$ of the respondents use some practices like only bed nets to avoid the access of Sand fly to human respectively $[7,8]$. This variability might be due to that fact that peoples in towns have more awareness about the use of bed net to avoid the access of sand fly to human compared to rural people.

Table 5. Respondents' practice in prevention and control of visceral leishmaniasis.

\begin{tabular}{|c|c|c|}
\hline \multirow{2}{*}{ Question items } & \multicolumn{2}{|c|}{ Level of response } \\
\hline & Frequency & Percentage $(\%)$ \\
\hline \multicolumn{3}{|c|}{$\begin{array}{l}\text { 1. Drug preference in the treatment of kala- } \\
\text { azar }\end{array}$} \\
\hline Specific medicine & 158 & 39.7 \\
\hline Indigenous medicine & 10 & 2.5 \\
\hline Do not know & 230 & 57.8 \\
\hline \multicolumn{3}{|c|}{$\begin{array}{l}\text { 2. Some traditional practices to prevent the } \\
\text { disease, VL }\end{array}$} \\
\hline Yes & 61 & 15.3 \\
\hline No & 337 & 84.7 \\
\hline \multicolumn{3}{|c|}{$\begin{array}{l}\text { 3. Some practices to prevent the access of } \\
\text { Sand fly to human }\end{array}$} \\
\hline Yes & 48 & 12.1 \\
\hline No & 350 & 87.9 \\
\hline \multicolumn{3}{|c|}{$\begin{array}{l}\text { 4. First choice for the treatment of the } \\
\text { suspected disease, VL }\end{array}$} \\
\hline Health post & 51 & 12.8 \\
\hline Public health center & 209 & 52.5 \\
\hline Private clinics & 138 & 34.7 \\
\hline Traditional healer & 0 & 0 \\
\hline \multicolumn{3}{|c|}{$\begin{array}{l}\text { 5. Which one of the following methods you } \\
\text { use to prevent Sand fly. }\end{array}$} \\
\hline Use of bed net & 28 & 7.0 \\
\hline Use of DDT & 32 & 8.0 \\
\hline Cleanness & 34 & 8.5 \\
\hline Note use any preventive methods & 281 & 70.6 \\
\hline Avoid outdoor sleeping & 23 & 5.8 \\
\hline
\end{tabular}

\subsection{Trends of Visceral Leishmaniasis in Libo Kemkem Wereda}

Health records of VL and patient registration books obtained from Addis Zemen hospital and Addis Zemen health center showed that the incidence of VL in the study area decreased steadily from 2006 to 2008, then gradually increased to five years (2008 to 2013) and decrease in the last three years (Figure 2). This gradual decrement of VL result is in agreement with the studies conducted Humera town, Ethiopia and Eastern Sudan, where the results showed that 
leishmaniasis cases decreased across the study years with the highest recorded in 2014 and There was a clear decline in the cumulative case and fatality rate from the year 2002 to the year 2015 respectively $[12,13]$. VL spread to thirteen new kebeles that were virtually free before 2009.

Currently, VL is distributed in 27 kebeles out of 37 kebeles in Libo Kemkem woreda. At the time of the 2003-2005 outbreaks, most of the kebeles were free from VL but nowadays only ten kebeles are free from VL. These are Derita, Goza, Mayitad, Womba, Asta Mariam, Bulbuha, Mendere Mariam, Libo Georgis, Ameno and Martadios.

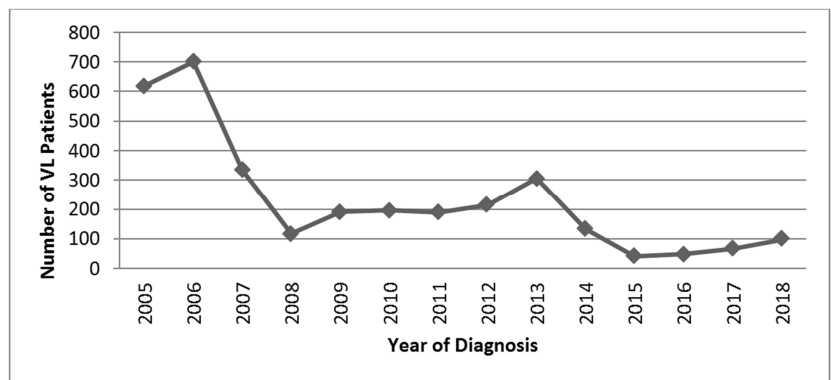

Figure 2. The trend of visceral leishmaniasis in Libo Kemkem wereda for the past fourteen years (April 2005-December 2018).

VL in the study area is more prevalent in males than in females (Figure 3). This finding is the same as the results of the studies conducted in Humera town, Ethiopia and Eastern Sudan, where Leishmaniasis cases were higher in males than females in all study years and The disease was observed to be more prevalent among adults and males respectively $[12,13]$. This might be due to the fact that males spend most of their time working outdoors, increasing the likelihood of being bitten by Sand fly vectors.

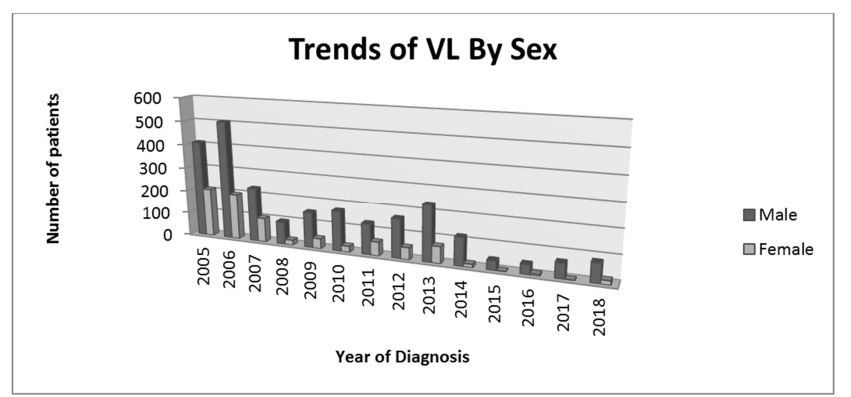

Figure 3. Trend of visceral leishmaniasis by sex in study area over the last fourteen years (April 2005-December 2018).

\section{Conclusions}

Although the great majority of the study participants have heard about VL, their level of knowledge about its transmission, symptoms and predisposing factors is low even after about 14 years of VL outbreak. Most knew the methods of VL prevention in spite of the fact that they did not practice them. Most people believe that education is important in the control of VL and VL is curable. Moreover, VL trend analysis shows that recently, VL is gradually increasing in the district. Therefore, a regular community-based education on transmission and implementation of preventive measures by health institutions and bureaus must be delivered to reverse the situation.

\section{References}

[1] Ready, P. D. Biology of Phlebotomine Sand Flies as Vectors of Disease Agents. Annu. Rev. Entomol. 58, 227-250 (2013).

[2] Chappuis, F., Sundar, S., Hailu, A., ... H. G.-N. reviews \& 2007, undefined. Visceral leishmaniasis: what are the needs for diagnosis, treatment and control? nature.com.

[3] Alvar, J., Yactayo, S., parasitology, C. B.-T. in \& 2006, undefined. Leishmaniasis and poverty. Elsevier.

[4] Alvar, J. et al. Leishmaniasis Worldwide and Global Estimates of Its Incidence. PLoS One 7, e35671 (2012).

[5] Argaw, D. et al. Risk Factors for Visceral Leishmaniasis among Residents and Migrants in Kafta-Humera, Ethiopia. PLoS Negl. Trop. Dis. 7, e2543 (2013).

[6] Singh, S., Reddy, D., Mishra, R., of, S. S.-T. A. journal \& 2006, undefined. Knowledge, attitude, and practices related to Kala-azar in a rural area of Bihar state, India. ASTMH.

[7] Berhe, M. et al. Knowledge Attitude and Practice towards Visceral Leishmaniasis among Residents and Health Professionals in Welkait District, Western Tigray, Ethiopia. $J$. Trop. Dis. 06, 4-11 (2018).

[8] Alemu, A. et al. Knowledge, attitude and practices related to visceral leishmaniasis among residents in Addis Zemen town, South Gondar, Northwest Ethiopia. BMC Public Health 13, (2013).

[9] Sayed, S. El, Journal, S. A.-A. \& 2001, undefined. Sociocultural aspects of Kala-azar among Masalit and Hawsa tribes. search.proquest.com.

[10] Siddiqui, N. A. et al. Awareness about kala-azar disease and related preventive attitudes and practices in a highly endemic rural area of India. Southeast Asian J. Trop. Med. Public Health 41, 1-12 (2010).

[11] Singh, S., Hasker, E., ... A. P.-T. medicine \& \& 2010, undefined. Risk factors for visceral leishmaniasis in India: further evidence on the role of domestic animals. Wiley Online Libr.

[12] Gebremichael Tedla, D., Bariagabr, F. H. \& Abreha, H. H. Incidence and Trends of Leishmaniasis and Its Risk Factors in Humera, Western Tigray. J. Parasitol. Res. 2018, 1-9 (2018).

[13] Adam, G. K. et al. Trend in cumulative cases and mortality rate among visceral leishmaniasis patients in Eastern Sudan: a 14-year registry, 2002-2015. Int. J. Infect. Dis. 51, 81-84 (2016). 